\title{
Approach to residual dizziness after successfully treated benign paroxysmal positional vertigo: effect of a polyphenol compound supplementation
}

This article was published in the following Dove Press journal:

Clinical Pharmacology: Advances and Applications

\author{
Augusto Pietro Casani, ' \\ Elena Navari,' Roberto Albera, ${ }^{2}$ \\ Giuseppe Agus, ${ }^{3}$ \\ Giacinto Asprella Libonati, ${ }^{4}$ \\ Giuseppe Chiarella, ${ }^{5}$ \\ Nicola Lombardo, ${ }^{6}$ \\ Vincenzo Marcelli, ${ }^{7}$ \\ Giovanni Ralli, ${ }^{8}$ \\ Leonardo Scotto di Santillo, \\ Roberto Teggi, ${ }^{10}$ Pasquale Viola, ${ }^{5}$ \\ Luigi Califano" "
}

'Department of Medical and Surgical Pathology, Otorhinolaryngology Section, Pisa

University, Pisa, Italy; ${ }^{2}$ Division of

Otorhinolaryngology, Department of

Surgical Sciences, University of Turin School

of Medicine, Turin, Italy;

${ }^{3}$ Otorhinolaryngology, Private Practice,

Cagliari, Italy; ${ }^{4}$ Ear, Nose and Throat

Department, Unit of Audiology, Vestibology

and Phoniatry, Madonna delle Grazie

Hospital, Matera, Italy; ${ }^{5}$ Department of

Experimental and Clinical Medicine, Unit of

Audiology and Phoniatrics, Magna Græcia

University, Catanzaro, Italy;

${ }^{6}$ Otorhinolaryngology Section, Mater

Domini University, Catanzaro, Italy;

${ }^{7}$ Department of Neuroscience, Vestibular

and Audiology Unit, University of Naples

"Federico II", Naples, Italy; ${ }^{8}$ Department of

Sense Organs, Sapienza University of Rome,

Rome, Italy; ${ }^{9}$ Vestibology and Vestibular

Rehabilitation Unit, Antero Micone Hospital,

Genoa, Italy; ${ }^{10} \mathrm{Ear}$, Nose and Throat

Department, San Raffaele Scientific Hospital,

Milan, Italy; "Audiovestibology Unit, G.

Rummo Hospital, Benevento, Italy

Correspondence: Augusto Pietro Casani Department of Surgical Pathology,

Medical, Molecular and Critical Area,

ENT Section, Pisa University Hospital, Via

Paradisa, 2, 56/24, Pisa, Italy

$\mathrm{Tel}+39050997496$

Email augusto.casani@unipi.it
Purpose: To assess if a polyphenol compound supplementation (Vertigoval ${ }^{\circledR}$ ) could improve residual dizziness earlier after benign paroxysmal positional vertigo (BPPV) and relieve patients from this disabling symptomatology.

Methods: In this prospective, multicentric study, 127 patients were randomized in the treatment group (TG), who received a 60-day supplementation, while 131 patients were randomized in the control group (CG), who did not receive any medication. The dizziness handicap inventory (DHI) score, static posturography, and the visual analog scale (VAS) for both dizziness (D-VAS) and nausea/vomit (N/V-VAS) were used as measures of outcome at baseline and after 30 and 60 days. Patients were asked about efficacy and tolerance to the treatment. Side effects were examined.

Results: A statistically significant greater decrease was established in the TG for DHI, DVAS, and N/V-VAS compared to the CG. On the other hand, static posturography did not show statistical differences between the two groups, though a better clinical improvement after 60-day supplementation was shown in the TG in comparison to the CG. We counted mild side effects in only 2 patients. Most patients reported an excellent or good efficacy and tolerance to the treatment.

Conclusion: Residual dizziness is a frequent condition of unknown origin that manifests as persistent disabling imbalance after successful repositioning maneuvers for BPPV. The decreasing postural control can affect the quality of life, contributing to falling and psychological problems. The supplementation with the polyphenol compound used in our study is safe, manageable, and appeared to be able to reduce subjective symptoms and improve instability earlier, decreasing the risk of potential complications.

Keywords: residual dizziness, benign, paroxysmal positional vertigo, BPPV, Vertigoval ${ }^{\circledR}$

\section{Introduction}

Benign paroxysmal positional vertigo (BPPV) represents the most frequent vestibular disorder in neuro-otological clinical practice with a prevalence in the general population of about $2.4 \%$. $^{1,2}$

Even if this disorder may arise at any time of life, it rarely manifests in adolescents, resulting more frequently in adults and elderly people. The peak of incidence is around the fifth to seventh decade of life. ${ }^{2-4}$

Recurrent, brief and violent crises of true vertigo triggered by horizontal and vertical movements of the head characterize the disorder. While the etiology of BPPV has still not been fully understood and is classified as idiopathic in more than 
$70 \%$ of cases, ${ }^{3}$ the pathogenesis of BPPV is on the other hand almost certain: it may be identified in the detachment of otoliths and in their displacement in one of the three semicircular canals. ${ }^{5}$

A careful anamnesis normally addresses the diagnosis of BPPV. The diagnosis will be confirmed by the clinical examination of the patient that employs specific diagnostic maneuvers according to which of the canals is involved. While the Dix-Hallpike maneuver is used in order to identify otoliths inside the posterior semicircular canal (PSC), the supine head roll test is used for the horizontal semicircular canal and the head-hanging maneuver for the anterior semicircular canal. A proper diagnostic approach means avoiding a series of useless and costly instrumental tests and enables clinicians to go ahead swiftly with the treatment.

The importance of timely recognition of BPPV derives also from the high incidence of this pathology in the elderly. This disorder prevents the capacity to carry out normal routine daily activities determining a significant increase in the risk of falling and consequent injury. ${ }^{6}$

Also, the treatment is through maneuver able to bring the detached otoliths back to the utricle. Most patients have a good recovery after the treatment. ${ }^{7}$ However, up to two-thirds of patients may perceive a prolonged and handicapping instability, lightheadedness and malaise also known as "residual dizziness." 8 This residual symptomatology after the resolution of BPPV is variably described among patients. Some patients also complain of nausea and vomiting. Previous studies reported an association with a condition of stress of the subject that may be correlated with the duration of the BPPV and number of recurrences. ${ }^{8,9}$ Some authors reported the duration of the residual symptoms of about 6-20 days. ${ }^{8-10}$ However, some patients recover later than others and some of these still present symptoms after 1 and 2 months. $^{2,11}$ To our knowledge, there is no accordance in the literature about any drug or any other measure to approach this residual disabling symptomatology.

In this study, we report the effect of 30- and 60-day supplementation with a polyphenol compound (Vertigoval $^{\circledR}$, Valeas, Milan, Italy) in patients with residual symptoms after successfully treated BPPV. Our main aim was to assess if this supplementation could earlier improve symptoms in this category of patients and relieve from the handicapping, and potential cause of fall, instability.

\section{Materials and methods}

In this prospective, multicentric, randomized study, 290 patients were recruited from different centers in Italy between January 2017 and November 2017. Participating centers were Benevento, Cagliari, Catanzaro, Genova, Matera, Milan, Naples, Pisa, Rome, and Turin. The enrollment of patients was made according to a randomization list taking into account the ratio $1: 1$ between the two groups of patients having the foresight to balance the two groups in each center. For this purpose, we have utilized the Lehmer algorithm using the number generator as reports in the Emilia Romagna sites (http://wwwservizi. regione.emilia-romagna.it/generatore/).

This study was approved by the Ethics Committee of the AOUP (Azienda Ospedaliero-Universitaria Pisana).

All the patients belonging to the study group underwent only routinely performed tests, without invasive or experimental procedures. Written informed consent was obtained from all participants and the study was conducted in accordance with the Declaration of Helsinki.

Inclusion criteria were the presence of dizziness eventually associated with neurovegetative symptoms after canalolithiasis of PSC BPPV ${ }^{2}$ successfully treated using canalith repositioning procedures (paroxysmal positional nystagmus is no more detectable by using an infrared/ video googles). The age had to be between 20 and 80 years old. Exclusion criteria were a post-traumatic or a post-neuritis BPPV, central nervous system disease, alcohol or drug addiction, uncontrolled hypertension, hypotension, or thyroid disease, severe coronary artery disease, severe renal and/or hepatic impairment, antiplatelet and/or anticoagulant therapy, pregnant or breastfeeding, chronic instability pre-existing at the onset of BPPV, known intolerance to the components of the supplementation, and poor compliance.

The recruited patients were randomized in the treatment group (TG), who took the polyphenol compound containing the recommended daily intake $(150 \mathrm{mg})$, one tablet two times in a day away from meals for 60 days. The supplementation is a polyphenol compound containing ViNitrox, Vitamin B6, Citicoline, Melissa officinalis, and Ginger. Compliance with supplementation and side effects were examined as self-reported by patients. Patients were also asked about efficacy and tolerance to the treatment as excellent, good, sufficient, or poor. The remaining patients were randomized in the control group (CG), who did not receive any supplementation. 
We evaluated all patients on the day of the recruitment (T0), after 30 (T30) and 60 (T60) days, by performing Dix-Hallpike maneuvers in order to exclude the presence of recurrence of BPPV.

The Italian version of the dizziness handicap inventory (DHI) score, ${ }^{12}$ static posturography, and the VAS for both dizziness (D-VAS) and nausea/vomit (N/V-VAS) were used as measures of outcome.

The DHI constitutes one of the most commonly used measures to assess dizziness, and it is based on patient's reported outcome. As known, the self-assessment questionnaire is formed by 25 items with a total score ranging from 0 to 100 on the basis of symptoms frequency.

Static posturography was performed by employing a dedicated device (Standard Vestibology Platform, SVeP stabilometric platform, Amplifon, Italy). The patients were asked to maintain their balance on a support, either rigid or with a $10-\mathrm{cm}$ rubber foam applied on, with the eyes open and eyes closed. For each condition, the following parameters were considered: the length (L) of the oscillations, expressed in millimeters and represented by the entire distance covered by the center of pressure of the subject, which is an index of the energy spent; the surface (S) of the body sway, expressed in square millimeters and represented by the confidence ellipse containing $90 \%$ of the sample position, indicating the precision of the system. The software automatically provided all measures.

Finally, patients were interviewed about their subjective sensation of dizziness and nausea/vomit, which were reported using the D-VAS and the N/V-VAS, respectively. The two end-points of the VAS were 0 (no sensation) and 100 (disabling and continuous sensation).

\section{Statistical analysis}

For each group and for each measure of outcome, we calculated the mean and the standard error of mean (SEM). For all the measures of outcome, we assessed differences inside each group within the timeframe using the paired samples Student $T$-test. Differences between the TG and the CG were evaluated using the independent sample Student $T$-test. For the DHI, we also provided the absolute difference (mean of the difference, delta) and the SEM within the established timeframe in order to assess differences between the two groups. We also determined the impact of age on DHI score classifying patients into one of the three age groups: younger adults (YA, age $\leq 40$ years), middle age adults (MA, age 41-60 years), or older adults (OA, age $>60$ years). DHI and VAS time profile of treatment response have been done using ANOVA for repeated measures and interaction treatment*time has been also included in the model. Significance was set at $P \leq 0.05$.

\section{Results}

Among the 290 patients recruited, 32 (11\%) were dropped out and were not considered for the statistical analysis. Conditions below the drop out were the presence of a recurrence in 2 cases (both patients belonged to the TG) and the occurrence of side effects in 2 cases. Among these, epigastric pain and agitation. The other patients were lost to the follow-up. However, the drops out were good balanced between the two groups having 15 patients in the TG and 17 patients in the CG. None of the enrolled patients suffered serious adverse events or had to change the basal therapy for new illnesses. Among the remaining 258 patients, 127 were randomized in the TG and 131 in the CG (Figure 1). In the TG, the average age was 50.6 (22-80) and there were 70 females and 57 males. In the CG, the average age was $50.2(20-80)$ and there were 77 females and 54 males. The period between the onset of symptoms and the enrollment of patients was 1-10 days.

No significant differences were present at baseline between the two groups about any of the considered outcome measures $(P>0.05)$. Both groups showed a statistically significant improvement of the DHI scores $(P \leq 0.001)$ both after 30 and after 60 days (Table 1). This improvement was greater in the TG $(P \leq 0.001)$ when we took into

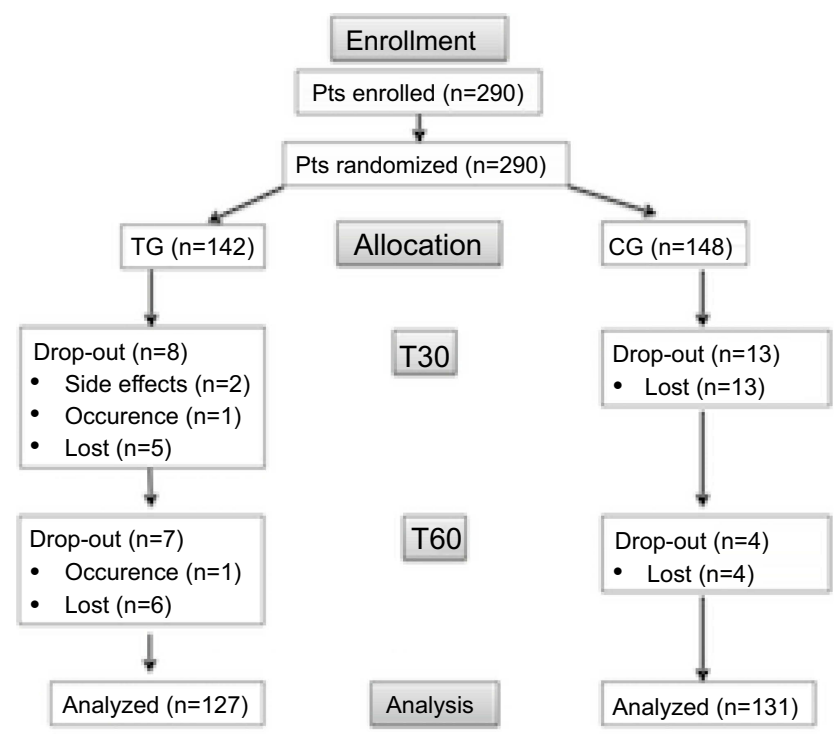

Figure I Flow diagram demonstrating patients (Pts) enrollment and progress in the randomized controlled trial.

Abbreviations: TG, treated group; CG, control group; T30, after 30 days; T60 after 60 days. 
Table I Results of the assessment with dizziness handicap inventory (DHI) score at baseline (T0) and after 30 days (T30) and after 60 days (T60) in the treated group (TG) and in the control group (CG). Mean \pm standard error of mean (SEM) of DHI values and absolute difference versus TO value (delta)

\begin{tabular}{|c|c|c|c|c|c|}
\hline & Patients (n) & & $\begin{array}{l}\text { TO } \\
\text { Mean } \pm \text { SEM }\end{array}$ & $\begin{array}{l}\text { T30 } \\
\text { Mean } \pm \text { SEM }\end{array}$ & $\begin{array}{l}\text { T60 } \\
\text { Mean } \pm \text { SEM }\end{array}$ \\
\hline CG & $13 \mid$ & $\begin{array}{l}\text { DHI values } \\
\text { Paired } t \text { test } \\
\text { (Absolute delta vs T0) }\end{array}$ & $\begin{array}{l}38.53 \pm 1.19 \\
- \\
-\end{array}$ & $\begin{array}{l}24.06 \pm 0.96 \\
* * * \\
(-14.47 \pm 0.92)\end{array}$ & $\begin{array}{l}17.18 \pm 0.29 \\
* * * \\
(-21.40 \pm 1.24)\end{array}$ \\
\hline TG & 127 & $\begin{array}{l}\text { DHI values } \\
\text { Paired } t \text { test } \\
\text { (Absolute delta vs T0) }\end{array}$ & $\begin{array}{l}41.09 \pm 1.31 \\
- \\
-\end{array}$ & $\begin{array}{l}20.74 \pm \mid .21 \\
* * * \\
(-20.35 \pm \mid 4.36)\end{array}$ & $\begin{array}{l}10.47 \pm 1.05 \\
* * * \\
(-30.61 \pm 1.33)\end{array}$ \\
\hline \multicolumn{2}{|c|}{$\begin{array}{l}\text { CG vs TG } \\
\text { Independent } t \text { test }\end{array}$} & $\begin{array}{l}\text { DHI values } \\
\text { Absolute delta vs T0 }\end{array}$ & $\begin{array}{l}\text { ns } \\
-\end{array}$ & $\begin{array}{l}\mathrm{ns} \\
* * *\end{array}$ & $\begin{array}{l}* * * \\
* * *\end{array}$ \\
\hline
\end{tabular}

Notes: ns, $P>0.05 ; * * * P \leq 0.001$.

Abbreviation: $\mathrm{ns}$, not significant.

account the delta: at $\mathrm{T} 30-38 \%$ for $\mathrm{CG}$ and $-56 \%$ for $\mathrm{TG}$ and at T60 $-50 \%$ for $\mathrm{CG}$ and $-75 \%$ for TG. Moreover, a difference $(P \leq 0.001)$ between $\mathrm{CG}$ and TG was detected also at T60 when the mean values of score were considered. Results are shown in detail in Table 1. ANOVA for repeated measures carried out on DHI values showed a significant interaction between treatment*time $(P=0.05)$, meaning a different profile of treatment response between the two group of patients in favor of the group treated.

About the impact of age on DHI, the differences observed both at $\mathrm{T} 30$ and $\mathrm{T} 60$ between $\mathrm{CG}$ and $\mathrm{TG}$ were less greater for YA than those observed for MA and OA patients $(P \leq 0.01$ and $P \leq 0.001)$. Data are reported in detail in Table 2 .

The D-VAS and N/V-VAS assessment in both groups showed a statistically significant improvement $(P \leq 0.001)$ of the baseline (T0) scores both after 30 and after 60 days (Table 4). The comparison between groups showed a greater decrease in the TG respect to the CG $(P \leq 0.001$, $P \leq 0.01$ only for N/V-VAS at T30). ANOVA for repeated measures showed a different result in the interaction treatment*time results between D-VAS and N/V-VAS. The interaction was statistically significant $(p=0.03)$ only in D-VAS.

The difference $\%$ vs T0 for D-VAS are at T30 $-25 \%$ for $\mathrm{CG}$ and $-49 \%$ for $\mathrm{TG}$ and at $\mathrm{T} 60-44 \%$ for $\mathrm{CG}$ and $-81 \%$ for TG. The difference $\%$ vs T0 for N/V-VAS are at T30 $-39 \%$ for the CG and $-58 \%$ for TG and at T60 $-62 \%$ for CG and $-87 \%$ for TG. Results about D-VAS and N/VVAS are summarized in Table 3.

The static posturography assessment in both groups (CG and TG) showed at each time (T30 and T60) always an improvement in $\mathrm{L}$ and $\mathrm{S}$ both when the measure was carried on rigid or soft support and when the eyes were kept open or closed. When measures were made on soft support, the TG seemed to show a better improvement than CG. No statistical differences between groups were found at each time of measurement. All the results about static posturography are presented in detail in Table 4.

Efficacy and tolerance to the polyphenol compound were reported as excellent or good in $81 \%$ and $94 \%$ at T30 and $91 \%$ and $98 \%$ at T60 of patients, respectively.

\section{Discussion}

Residual dizziness is a common experience that manifests as persistent imbalance after successful repositioning maneuvers for BPPV. These symptoms may affect the quality of life and prevent carrying out daily activities. The decreasing postural control can contribute to falling and psychological problems. ${ }^{13}$ Although many hypotheses have been postulated, the origin of this disturbance is not yet clear. ${ }^{10}$ Several medications have been proposed to approach these symptoms ${ }^{14-17}$ but nothing has yet proved to provide relief for residual dizziness compared to placebo. ${ }^{10}$ The most used molecule to approach residual dizziness after BPPV is betahistine dihydrochloride, but its results are conflicting. Guneri and Kustutan ${ }^{14}$ found that $48 \mathrm{mg}$ of betahistine daily, in addition to Epley maneuver, gave more effective results than Epley maneuver alone or combined with placebo in improving symptoms. On the other hand, in the randomized controlled clinical trial by Acar et $\mathrm{al}^{15}$, the authors did not find any difference between patients who took betahistine, trimetazidine or gingko biloba and patients who did not receive any medication. 
Table 2 Impact of age on dizziness handicap inventory (DHI) score in the treated group (TG) and in the control group (CG). Mean of absolute difference versus T0 (delta)

\begin{tabular}{|c|c|c|c|c|}
\hline \multirow[b]{2}{*}{$\begin{array}{l}\text { Age } \\
\text { (years) }\end{array}$} & \multirow[b]{2}{*}{ Group } & \multirow[b]{2}{*}{ Patients (n) } & \multicolumn{2}{|c|}{$\begin{array}{l}\text { Absolute delta } \\
\text { vs T0 } \\
\text { (mean value) }\end{array}$} \\
\hline & & & T30 & T60 \\
\hline \multirow{3}{*}{$\begin{array}{l}\leq 40 \\
\text { (Younger Adults) }\end{array}$} & CG & 29 & -15.2 & -20.1 \\
\hline & TG & 24 & -18.6 & -28.9 \\
\hline & \multicolumn{2}{|c|}{ Independent $t$ test } & ns & $*$ \\
\hline \multirow{3}{*}{$\begin{array}{l}>40 \text { to } \leq 60 \\
\text { (Middle Age Adults) }\end{array}$} & CG & 73 & -15.0 & -22.9 \\
\hline & TG & 74 & -20.7 & -30.2 \\
\hline & \multicolumn{2}{|c|}{ Independent $t$ test } & ** & $* *$ \\
\hline \multirow{3}{*}{$\begin{array}{l}>60 \\
\text { (Older Adults) }\end{array}$} & CG & 28 & -12.9 & -19.43 \\
\hline & TG & 27 & -21.9 & -33.3 \\
\hline & \multicolumn{2}{|c|}{ Independent $t$ test } & ** & $* * *$ \\
\hline
\end{tabular}

Notes: ns, $P>0.05 ; * P \leq 0.05 ; * * P \leq 0.01 ; * * * P \leq 0.001$.

Abbreviations: T0, baseline; T30, after 30 days; T60 after 60 days.

Kim et $\mathrm{al}^{16}$ investigated the role of vestibular suppressant in a randomized controlled trial. According to the authors, dimenhydrinate could be helpful in preventing residual dizziness. However, side effects of this molecule need to be known and its use is reserved to selected patients for a limited number of days. In the same way, there is no consensus about the use of anxiolytic suggested by Jung et $\mathrm{al}^{17}$.

In this multicentric study, our main purpose was to assess if a polyphenol compound could provide benefit to the category of patients studied. The analysis has been carried out on a great sample of patients, and to our knowledge, there are no previous similar experiences in the literature. Because of the features of this medication, it is overall safe and can be easily employed to approach also elderly that are mostly included in this category of patients.

Our results showed an overall progressive improvement of all the measures of outcome considered in both groups after 30 and 60 days. This was expected and underlines the natural relief of symptoms in most patients. However, we noticed a more significant improvement in the TG, in particular after 60 days of treatment with the polyphenol compound. The decision to evaluate up to 60 days the effect of the polyphenol

Table 3 Results of the assessment with D-VAS (dizziness VAS) and N/V-VAS (nausea and vomit VAS) at baseline (T0) and after 30 (T30) and 60 (T60) days in the treated group (TG) and in the control group (CG). Mean \pm standard error of mean (SEM)

\begin{tabular}{|c|c|c|c|c|c|}
\hline & Patients (n) & & $\begin{array}{l}\text { TO } \\
\text { Mean } \pm \text { SEM }\end{array}$ & $\begin{array}{l}\text { T30 } \\
\text { Mean } \pm \text { SEM }\end{array}$ & $\begin{array}{l}\text { T60 } \\
\text { Mean } \pm \text { SEM }\end{array}$ \\
\hline CG & 97 & $\begin{array}{l}\text { D-VAS values } \\
\text { Paired } t \text { test } \\
(\% \text { vs T0) }\end{array}$ & $\begin{array}{l}48.85 \pm 2.02 \\
- \\
(-)\end{array}$ & $\begin{array}{l}36.95 \pm 1.75 \\
* * * \\
(-24.4 \%)\end{array}$ & $\begin{array}{l}27.08 \pm 1.91 \\
* * * \\
(-44.6 \%)\end{array}$ \\
\hline TG & 94 & $\begin{array}{l}\text { D-VAS values } \\
\text { Paired } t \text { test } \\
\text { (\% vs T0) }\end{array}$ & $\begin{array}{l}51.21 \pm 1.97 \\
-\end{array}$ & $\begin{array}{l}26.05 \pm 1.65 \\
* * * \\
(-49.1 \%)\end{array}$ & $\begin{array}{l}9.96 \pm 1.47 \\
* * * \\
(-80.6 \%)\end{array}$ \\
\hline & & $\begin{array}{l}\text { CG vs TG } \\
\text { Independent } t \text { test }\end{array}$ & ns & $* * *$ & $* * *$ \\
\hline CG & 97 & $\begin{array}{l}\text { N/V-VAS values } \\
\text { Paired } t \text { test } \\
(\% \text { vs T0) }\end{array}$ & $\begin{array}{l}30.67 \pm 2.10 \\
-\end{array}$ & $\begin{array}{l}|8.86 \pm| .57 \\
* * * \\
(-38.5 \%)\end{array}$ & $\begin{array}{l}\mid 1.70 \pm 1.80 \\
* * * \\
(-61.9 \%)\end{array}$ \\
\hline \multirow[t]{2}{*}{ TG } & 94 & $\begin{array}{l}\text { N/V-VAS values } \\
\text { Paired } t \text { test } \\
\text { (\% vs T0) }\end{array}$ & $\begin{array}{l}28.83 \pm 2.21 \\
-\end{array}$ & $\begin{array}{l}|2 .| 6 \pm|.6| \\
* * * \\
(-57.8 \%)\end{array}$ & $\begin{array}{l}3.88 \pm 0.90 \\
* * * \\
(-86.5 \%)\end{array}$ \\
\hline & & $\begin{array}{l}\text { CG vs TG } \\
\text { Independent } t \text { test }\end{array}$ & ns & $* *$ & $* * *$ \\
\hline
\end{tabular}

Notes: ns, $P>0.05 ; * * P \leq 0.01 ; * * * P \leq 0.001$.

Abbreviations: T0, baseline; T30, after 30 days; T60 after 60 days; ns, not significant.. 
Table 4 Results of the assessment with static posturography at baseline (T0) and after 30 (T30) and 60 (T60) days in the treated group (TG) and in the control group (CG). Mean \pm standard error of mean (SEM)

\begin{tabular}{|c|c|c|c|c|c|}
\hline & & Patients (n) & $\begin{array}{l}\text { TO } \\
\text { Mean } \pm \text { SEM }\end{array}$ & $\begin{array}{l}\text { T30 } \\
\text { Mean } \pm \text { SEM (\%) } \\
\text { Paired } t \text { test }\end{array}$ & $\begin{array}{l}\text { T60 } \\
\text { Mean } \pm \text { SEM (\%) } \\
\text { Paired } t \text { test }\end{array}$ \\
\hline \multirow[t]{2}{*}{$\begin{array}{l}\text { S on rigid support with } \\
\text { the eyes open }\end{array}$} & CG & n.67 & $\begin{array}{l}302.7 \pm 28.3 \\
-\end{array}$ & $\begin{array}{l}264.4 \pm 20.9 \\
(-12.7 \%) \\
*\end{array}$ & $\begin{array}{l}239.9 \pm 18.2 \\
(-20.7 \%) \\
*\end{array}$ \\
\hline & TG & 59 & $\begin{array}{l}269.0 \pm 21.6 \\
-\end{array}$ & $\begin{array}{l}241.7 \pm 21.5 \\
(-10.1 \%) \\
\text { ns }\end{array}$ & $\begin{array}{l}\mid 91.9 \pm 17.7 \\
(-28.7 \%) \\
* * *\end{array}$ \\
\hline \multirow[t]{2}{*}{$\begin{array}{l}\text { S on rigid support with } \\
\text { the eyes closed }\end{array}$} & CG & 67 & $\begin{array}{l}530.1 \pm 70.5 \\
-\end{array}$ & $\begin{array}{l}419.2 \pm 26.2 \\
(-20.9 \%) \\
*\end{array}$ & $\begin{array}{l}384.7 \pm 27.4 \\
(-27.4 \%) \\
*\end{array}$ \\
\hline & TG & 59 & $\begin{array}{l}498.0 \pm 40.0 \\
-\end{array}$ & $\begin{array}{l}401.3 \pm 32.7 \\
(-19.4 \%) \\
\text { ns }\end{array}$ & $\begin{array}{l}329.7 \pm 26.0 \\
(-33.8 \%) \\
* * *\end{array}$ \\
\hline \multirow[t]{2}{*}{$\begin{array}{l}\text { S on soft } \\
\text { support with } \\
\text { the eyes open }\end{array}$} & CG & 55 & $\begin{array}{l}499.9 \pm 57.0 \\
-\end{array}$ & $\begin{array}{l}435.8 \pm 76.6 \\
(-12.8 \%) \\
\text { ns }\end{array}$ & $\begin{array}{l}364.5 \pm 58.82 \\
(-27.1 \%) \\
*\end{array}$ \\
\hline & TG & 50 & $\begin{array}{l}417.0 \pm 43.7 \\
-\end{array}$ & $\begin{array}{l}323.8 \pm 37.7 \\
(-22.4 \%) \\
* * *\end{array}$ & $\begin{array}{l}265.8 \pm 38.4 \\
(-36.3 \%) \\
* * *\end{array}$ \\
\hline \multirow[t]{2}{*}{$\begin{array}{l}\text { S on soft } \\
\text { support with } \\
\text { the eyes closed }\end{array}$} & CG & 55 & $\begin{array}{l}1014.0 \pm 151.4 \\
-\end{array}$ & $\begin{array}{l}878.1 \pm \mid 20.2 \\
(-\mid 3.4 \%) \\
\text { ns }\end{array}$ & $\begin{array}{l}831.9 \pm 124.5 \\
(-18.0 \%) \\
\text { ns }\end{array}$ \\
\hline & TG & 50 & $\begin{array}{l}|47| .0 \pm 259.4 \\
-\end{array}$ & $\begin{array}{l}1189.3 \pm 228.9 \\
(-19.2 \%) \\
*\end{array}$ & $\begin{array}{l}998.1 \pm 219.4 \\
(-32.1 \%) \\
* * *\end{array}$ \\
\hline \multirow[t]{2}{*}{$\begin{array}{l}\mathrm{L} \text { on rigid support with } \\
\text { the eyes open }\end{array}$} & CG & 67 & $386.5 \pm 31.6$ & $\begin{array}{l}349.6 \pm 31.1 \\
(-9.5 \%) \\
* *\end{array}$ & $\begin{array}{l}324.0 \pm 31.4 \\
(-16.2 \%) \\
* * *\end{array}$ \\
\hline & TG & 59 & $382.5 \pm 27.3$ & $\begin{array}{l}329.1 \pm 25.5 \\
(-14.0 \%) \\
* * *\end{array}$ & $\begin{array}{l}272.0 \pm 23.5 \\
(-28.9 \%) \\
* * *\end{array}$ \\
\hline \multirow[t]{2}{*}{$\begin{array}{l}\mathrm{L} \text { on rigid support with } \\
\text { the eyes closed }\end{array}$} & CG & 67 & $606.1 \pm 44.5$ & $\begin{array}{l}539.7 \pm 47.5 \\
(-11.0 \%) \\
* *\end{array}$ & $\begin{array}{l}477.3 \pm 43.7 \\
(-21.3 \%) \\
* * *\end{array}$ \\
\hline & TG & 59 & $613.1 \pm 42.6$ & $\begin{array}{l}532.1 \pm 40.7 \\
(-13.2 \%) \\
* * *\end{array}$ & $\begin{array}{l}4 \mid 3.2 \pm 33.2 \\
(-32.6 \%) \\
* * *\end{array}$ \\
\hline \multirow[t]{2}{*}{$\begin{array}{l}\mathrm{L} \text { on soft } \\
\text { support with } \\
\text { the eyes open }\end{array}$} & CG & 55 & $543.3 \pm 52.3$ & $\begin{array}{l}514.9 \pm 53.5 \\
(-5.2 \%) \\
*\end{array}$ & $\begin{array}{l}493.9 \pm 57.0 \\
(-9.1 \%) \\
* *\end{array}$ \\
\hline & TG & 50 & $510.8 \pm 46.3$ & $\begin{array}{l}433.8 \pm 4 I .4 \\
(-15.1 \%) \\
* * *\end{array}$ & $\begin{array}{l}366.0 \pm 38.7 \\
(-28.3 \%) \\
* * *\end{array}$ \\
\hline
\end{tabular}

(Continued) 
Table 4 (Continued).

\begin{tabular}{|c|c|c|c|c|c|}
\hline & & Patients (n) & $\begin{array}{l}\text { TO } \\
\text { Mean } \pm \text { SEM }\end{array}$ & $\begin{array}{l}\text { T30 } \\
\text { Mean } \pm \text { SEM (\%) } \\
\text { Paired } t \text { test }\end{array}$ & $\begin{array}{l}\text { T60 } \\
\text { Mean } \pm \text { SEM (\%) } \\
\text { Paired } t \text { test }\end{array}$ \\
\hline $\begin{array}{l}\text { L on soft } \\
\text { support with } \\
\text { the eyes closed }\end{array}$ & $\begin{array}{l}\mathrm{CG} \\
\mathrm{TG}\end{array}$ & $\begin{array}{l}55 \\
50\end{array}$ & $\begin{array}{l}895.5 \pm 78.4 \\
1021.2 \pm \mid 13.8\end{array}$ & $\begin{array}{l}892.7 \pm 94.9 \\
(-0.3 \%) \\
\text { ns } \\
890.8 \pm 124.1 \\
(-12.8 \%) \\
* *\end{array}$ & $\begin{array}{l}832.9 \pm 99.0 \\
(-7.0 \%) \\
\text { ns } \\
741.0 \pm 106.4 \\
(-27.4 \%) \\
* * *\end{array}$ \\
\hline
\end{tabular}

Notes: No statistically significant difference (Independent $t$ test; $P>005)$ between group in any comparison at each time (T0, T30, T60) was found. ns, $P>0.05 ; * P \leq 0.05$; $* * P \leq 0.01$; ***P $\leq 0.00 \mathrm{I}$.

Abbreviations: S, surface; L, length; T0, baseline; T30, after 30 days; T60 after 60 days; ns, not significant.

supplementation comes from a previous experience that highlighted residual dizziness up to 60 days after successful repositioning treatment in patients with BPPV. ${ }^{18}$ The treatment up to 60 days could keep under control the possible exacerbations during the progressive vestibular compensation that is very different among patients because of multi-factor variables. The DHI time profiles of the two groups (TG vs CG) are different, meaning a different treatment response over time in favor of the group treated with the polyphenol compound we used. Patients enrolled in the TG showed a greater decrease of the DHI score within the timeframe compared to patients of the CG. The validity of this score is supported by a recent systematic review that describes the DHI as a good and validated instrument applicable also in adults with vestibular impairment. ${ }^{19}$ The supplementation seems to provide a greater relief from symptoms in patients older than 40 years. Since a faster recovery might decrease the risk of falling, which is above all pronounced in older patients, this data are particularly interesting.

The lowest subjective disturbance complained by patients who took the supplementation is also supported by both VAS. VAS constitutes a simple and rapid tool for symptoms assessment. ${ }^{20}$ Both DHI and VAS provide useful information about the influence of symptoms on the quality of life of patients with vestibular dysfunction and, together, may contribute to a better comprehension of the clinical condition and assist monitoring of the therapeutic approach. Surely, a lower perception of the disturbance might prevent the potential psychological complications described in this affection.

Tolerance and efficacy of the therapy were judged as excellent and good by most patients. Side effects manifested in a minority of patients with a mild symptomatology, making this medication overall sure and manageable.

The results we found can be easily supported by the components of the polyphenol compound we used. Citicoline and Vitamin B6 might facilitate the function of the central vestibular system having a protective effect on microvascular circulation. Yet, Melissa seems to be able to potentiate the gamma-aminobutyric acid (GABA) receptors alleviating the stress, which has been counted among the conditions below the residual instability after BPPV, as previously reported. The antiemetic power of ginger, on the other hand, was known since antiquity. The last component is ViNitrox, a synergistic combination of apple and grape polyphenols that has been demonstrated to have a remarkable vasodilator effect through endothelial nitric oxide synthase (NOS) and antioxidant activity. The combination seems effective in at least partially restoring the microvascular impairment in these patients improving also the cognitive function.

Usefully, a recent article published by Ulivi et $\mathrm{al}^{21}$ reports that the supplementation for 60 days with the polyphenol compound we studied reduces oxidative stress load in patients with a pre-existing imbalance, improving dizziness symptoms. Even if the study has been carried out on patients suffering from chronic dizziness because of the underlying small vessel disease, the mechanisms below the symptom's improvement in this category of patients can be the same able to take relief to the patients recruited in our study.

To our knowledge, static posturography has never been proposed and used as a measure to assess the outcome of patients suffering from residual dizziness after BPPV. Dynamic posturography has been rather employed by Vaduva et $\mathrm{al}^{11}$ to promote vestibular compensation in a recent study. The results obtained in our study are partially 
discordant. This can be due to the extremely complex interactions among sensory, motor, and central processes involved in posture and balance. The improved values in both groups within the timeframe can be easily explained by the natural and progressive improvement of the symptoms. However, also in this case, we detected a more pronounced decrease in the TG as perhaps further confirmation of the beneficial effect of the supplementation.

The main limitation of our study is the non-doubleblinded design together with the lack of a placebo group able to clarify if the results we found can be partially due to the time passing. Surely, further studies are needed in order to confirm the encouraging data detected in this study.

\section{Conclusion}

Residual dizziness is a frequent condition of unknown origin that manifests as persistent disabling imbalance after successful repositioning maneuvers for BPPV. The decreasing postural control can affect the quality of life contributing to falling and psychological problems. Several medications have been proposed to approach these symptoms but the results reported are conflicting. The supplementation with the polyphenol compound examined in our study is safe, manageable, and might be able to reduce subjective symptoms and improve instability earlier, decreasing the risk of potential complications.

\section{Disclosure}

The authors declare no conflicts of interest regarding this article.

\section{References}

1. Von Brevern M, Radtke A, Lezius F, Feldmann M, Ziese T, Lempert T. Epidemiology of benign paroxysmal positional vertigo: a population based study. J Neurol Neurosurg Psychiatry. 2007;78:710-715. doi:10.1136/jnnp.2006.100420

2. Bhattacharyya N, Gubbels SP, Schwartz SR, et al. Clinical practice guideline: benign paroxysmal positional vertigo (Update). Otolaryngol Head Neck Surg. 2017;156(3suppl):S1-S47. doi:10.1177/0194599816 689667

3. Baloh RW, Honrubia V, Jacobson KM. Benign positional vertigo: clinical and oculographic features in 240 cases. Neurology. 1987;37:371-378. doi:10.1212/wnl.37.3.371

4. Uneri A, Polat S. Vertigo, dizziness and imbalance in the elderly. $J$ Laryngol Otol. 2008;122:466-469. doi:10.1017/S0022215107000424

5. Nuti D, Masini M, Mandalà M. Benign paroxysmal positional vertigo and its variants. Handb Clin Neurol. 2016;137:241-256. doi:10.1016/ B978-0-444-63437-5.00018-2
6. Balatsouras DG, Koukoutsis G, Fassolis A, Moukos A, Apris A. Benign paroxysmal positional vertigo in the elderly: current insights. Clin Interv Aging. 2018;13:2251-2266. doi:10.2147/CIA.S144134

7. Albera A, Boldreghini M, Canale A, Albera R, Gervasio CF. Vertigo returning to the sitting position after the Semont manoeuvre. Is it a prognostic? Acta Otorhinolaryngol Ital. 2018;38:145-150. doi:10.14639/0392-100X-1815

8. Seok JI, Lee HM, Yoo JH, Lee DK. Residual dizziness after successful repositioning treatment in patients with benign paroxysmal positional vertigo. J Clin Neurol. 2008;4:107-110. doi:10.3988/jen.2008.4.3.107

9. Faralli M, Ricci G, Ibba MC, Crognoletti M, Longari F, Frenguelli A. Dizziness in patients with recent episodes of benign paroxysmal positional vertigo: real otolithic dysfunction or mental stress? $J$ Otolaryngol Head Neck Surg. 2009;38:375-380.

10. Giommetti G, Lapenna R, Panichi R, et al. Residual dizziness after successful repositioning maneuver for idiopathic benign paroxysmal positional vertigo: a review. Audiol Res. 2017;7:178. doi:10.4081/ audiores.2017.178

11. Vaduva C, Estéban-Sánchez J, Sanz-Fernández R, Martín-Sanz E. Prevalence and management of post-BPPV residual symptoms. Eur Arch Otorhinolaryngol. 2018;275:1429-1437. doi:10.1007/s00405-0184980-x

12. Colnaghi S, Rezzani C, Gnesi M, et al. Validation of the Italian version of the dizziness handicap inventory, the situational vertigo questionnaire, and the activity-specific balance confidence scale for peripheral and central vestibular symptoms. Front Neurol. 2017;8:528. doi:10.3389/fneur.2017.00528

13. Teggi R, Giordano L, Bondi S, Fabiano B, Bussi M. Residual dizziness after successful repositioning maneuvers for idiopathic benign paroxysmal positional vertigo in the elderly. Eur Arch Otorhinolaryngol. 2011;268:507-511. doi:10.1007/s00405-010-1422-9

14. Guneri EA, Kustutan O. The effects of betahistine in addition to epley maneuver in posterior canal benign paroxysmal positional vertigo. Otolaryngol Head Neck Surg. 2012;146:104-108. doi:10.1177/0194599811419093

15. Acar B, Karasen RM, Buran Y. Efficacy of medical therapy in the prevention of residual dizziness after successful repositioning maneuvers for benign paroxysmal positional vertigo (BPPV). B-ENT. 2015; $11: 117-121$.

16. Kim MB, Lee HS, Ban JH. Vestibular suppressants after canalith repositioning in benign paroxysmal positional vertigo. Laryngoscope. 2014;124:2400-2403. doi:10.1002/lary.24741

17. Jung HJ, Koo JW, Kim CS, Kim JS, Song JJ. Anxiolytics reduce residual dizziness after successful canalith repositioning maneuvers in benign paroxysmal positional vertigo. Acta Otolaryngol. 2012;132:277-284. doi:10.3109/00016489.2011.637179

18. Benazzo M, Cerchiai N, Comacchio F, et al. Valutazione sperimentale controllata di un nuovo preparato nutraceutico nel trattamento della fase post-critica del deficit vestibolare acuto e della vertigine posizionale benigna. Argomenti Di Acta ORL Italica. 2016;10:1-10.

19. Fong E, Li C, Aslakson R, Agrawal Y. Systematic review of patientreported outcome measures in clinical vestibular research. Arch Phys Med Rehabil. 2015;96:357-365. doi:10.1016/j.apmr.2014.09.017

20. Toupet M, Ferrary E, Grayeli AB. Visual analog scale to assess vertigo and dizziness after repositioning maneuvers for benign paroxysmal positional vertigo. J Vest Res. 2011;2:235-241.

21. Ulivi L, Maccarrone M, Giannini N, et al. Oxidative stress in cerebral small vessel disease dizziness patients, basally and after polyphenol compound supplementation. Curr Mol Med. 2018;18:160-165. doi:10.2174/1566524018666180720165055 


\section{Publish your work in this journal}

Clinical Pharmacology: Advances and Applications is an international, peer-reviewed, open access journal publishing original research, reports, reviews and commentaries on all areas of drug experience in humans. The manuscript management system is completely online and includes a very quick and fair peer-review system, which is all easy to use. Visit http://www.dovepress.com/testimonials.php to read real quotes from published authors.

Submit your manuscript here: https://www.dovepress.com/clinical-pharmacology-advances-and-applications-journal 